\title{
Red Meat Intake and Risk of Rheumatoid Arthritis: A Categorical and Dose-Response Meta-Analysis
}

\author{
WeiWei Chen \\ Zhejiang Chinese Medical University \\ Ke Liu \\ Zhejiang Chinese Medical University \\ Qing Su \\ Zhejiang Chinese Medical University \\ Xinxian Sang \\ Zhejiang Chinese Medical University \\ Yihan $\mathrm{Hu}$ \\ Zhejiang Chinese Medical University

\section{Yaxuan Zhuang} \\ Zhejiang Chinese Medical University \\ Zhixing He \\ Zhejiang Chinese Medical University

\section{Lin Huang} \\ Zhejiang Chinese Medical University \\ Yingying Mao \\ Zhejiang Chinese Medical University \\ Ding Ye ( $\nabla$ yeding@zcmu.edu.cn ) \\ Zhejiang Chinese Medical University https://orcid.org/0000-0001-6654-7832
}

\section{Research article}

Keywords: red meat intake, rheumatoid arthritis, meta- analysis, dose-response

Posted Date: September 8th, 2021

DOI: https://doi.org/10.21203/rs.3.rs-871604/v1

License: (c) (1) This work is licensed under a Creative Commons Attribution 4.0 International License. Read Full License 


\section{Abstract}

Objective: Findings from previous observational studies on the association between red meat intake and risk of rheumatoid arthritis (RA) are inconsistent. Therefore, we aimed to evaluate the impact of red meat intake on the incidence of RA by metaanalysis.

Methods: PubMed and Web of Science were searched for eligible observational studies regarding the association between red meat intake and the risk of RA until June 30, 2021. Risk estimates with corresponding 95\% confidence interval $(95 \% \mathrm{Cl})$ were pooled. Subgroup analysis and meta-regression analysis were performed to explore the potential sources of heterogeneity. Sensitivity analysis and publication bias test were also carried out.

Results: A total of eleven studies were selected, involving 4 cohort studies with 5203 identified cases from 349776 individuals and 7 case-control studies with 3762 cases and 6856 controls. The pooled risk estimate of RA risk was 0.94 (95\% Cl: 0.77 to 1.15 ) for ever versus non/occasional red meat intake, while high dose of red meat intake increased the risk of RA (OR: 1.26, $95 \% \mathrm{Cl}: 1.07$ to $1.50)$ in the categorical meta-analysis. Dose-response meta-analysis suggested a non-linear dose-response relationship between red meat intake and RA $(P=0.028)$. Red meat intake was found to be a risk factor of RA when the dose ranged from 96 to 166 g/day.

Conclusion: High dose of red meat intake could increase the risk of RA. Mechanistic studies are warranted to clarify the aetiologic pathways through which high dose of red meat intake may promote RA.

\section{Introduction}

Rheumatoid arthritis (RA) is a chronic systemic autoimmune disease that corrodes arthrosis and causes progressive articular damage [1]. The annual incidence rate of RA was 14.9\% in 2017, which has increased $8.2 \%$ compared with that in 1990 around the world [2]. It was estimated that 20 to 30 percent of RA patients would be invalidity for work permanently without any medical treatment within two to three years of diagnosis [3].

Accumulating environmental risk factors have been found to play an important role in RA, such as smoking, breastfeeding, silica exposure and educational level [4-7]. Recently, it has received growing attention that dietary pattern and nutrients are potential modifiable factors affecting the occurrence and development of RA. For example, a population-based case-control study found that Mediterranean diet can protect against RA in the Swedish epidemiological investigation of RA [8]. Likewise, a large-scaled case-control study showed that consumption of oily fish was associated with a moderately reduced risk of RA [9]. In addition, a meta-analysis provided sufficient evidence that high intake of total vitamin D reduces the incidence of RA [10].

Red meat as a fundamental component of daily diet in humans, its association with RA has been gradually concerned, while the findings were controversial. In the cohort of Nurses' Health Study (NHS) and NHSII, Hu et al [11] found that lower red meat consumption had a protective effect on the risk of early-onset RA during 3,678,104 person-years. Also, another large cohort study consisting of 80,551 postmenopausal women in the United States came to the similar conclusion that red meat can promote the risk of RA [12]. However, several studies showed no statistically significant association between red meat intake and the incidence of RA [13-15]. Moreover, little is known regarding the dose-response relationship between the consumption of red meat and risk of RA.

Therefore, we performed a categorical and dose-response meta-analysis to clarify the relationship between red meat intake and risk of RA.

\section{Methods}

The study was registered in the International Prospective Register of Systematic Reviews (PROSPERO: CRD42021267568). The PRISMA checklist for reporting the meta-analysis is shown in Supplementary Table 1.

\section{Search strategy}


PubMed and Web of Science were searched for observational studies investigating the association of red meat intake with risk of RA until June 30, 2021, without language restrictions. The subject terms were established as follow: ("meat" or "beef" or "veal" or "pork" or "lamb" or "mutton" or "horse" or "goat" or "bacon" or "ham" or "sausage" or "salami" or "hot dogs") and ("rheumatoid arthritis" or "RA"). In addition, references of related studies were also checked to identify additional publications of interest.

\section{Inclusion and exclusion criteria}

Studies meeting the following criteria were included: (1) study type was an observational study; (2) directly reported odds ratio $(\mathrm{OR})$ or hazards ratio (HR) or relative risk (RR) with $95 \%$ confidence interval $(\mathrm{Cl})$ or indirectly provided relevant data for calculation; (3) if study populations overlapped, the one with larger sample size was included.

The exclusion criteria were as follows: (1) animal study, review, meta-analysis, letter or comment; (2) no access to full text; (3) with insufficient data to obtain risk estimates with $95 \% \mathrm{Cl}$.

Two authors (Chen W and Liu K) independently evaluated the retrieved literature in full text, and discrepancies were resolved by a third author (Ye D).

\section{Data extraction}

Data was extracted cross-checked by two researchers (Chen W and Liu K) independently from eligible studies. The extracted information included name of first author, publication year, area, age, gender, type of study design, follow-up period, sample size, dose of red meat intake and the maximally adjusted OR, RR or HR with corresponding $95 \% \mathrm{Cl}$.

\section{Quality assessment}

The Newcastle-Ottawa Scale (NOS) [16] was used to evaluate the quality of included studies with scores ranging from 0 to 9 points. Studies with a quality score of no less than 7 points were considered as high quality. Two reviewers (Sang X and Zhuang Y) assessed the quality, and discrepancies were resolved by consensus and discussion.

\section{Statistical analysis}

All analyses were performed within Stata version 13 (Stata Corp LP, College Station, TX). Cochran's Q test and $\mathrm{I}^{2}$ statistics were utilized to assess the heterogeneity across the included studies [17]. Random-effects model was preferred when $p<0.10$ and $P\rangle$ $50 \%$; otherwise, fixed-effect model was applied.

In the categorical meta-analysis, ever red meat intake was compared with non/occasional red meat intake, which was defined by study-specific reference ranges. If the group of ever red meat intake was set up into multiple categories, we combined the effect estimates of different categories into a single value in each study. When the study reported mean and standard deviation (SD) of red meat intake between RA patients and controls rather than OR value, we transformed standardized mean difference (SMD) to OR according to the formula of In OR= SMD [18]. If the study provided median and range of red meat intake, we computed mean and SD by the method of Hozo et al [19]. We also pooled the risk estimates comparing the highest with the lowest red meat intake among the studies with equal or more than three different categories of red meat intake. Moreover, subgroup analysis and metaregression analysis were further performed based on food culture (western, oriental and Arab diet), publication year ( $<2018$ and 2018), quality score ( $\geq 7$ and $<7)$, sample size $(\geq 1000$ and $<1000)$. Furthermore, sensitivity analysis was used to check stability of the results by omitting one study at a time and combining the effect values of the remaining studies. Begg's test and Egger's test $[20,21]$ were used to evaluate publication bias.

For the dose-response meta-analysis, we used the method described by Greenland and Longnecker [22] to estimate the doseresponse relationship between red meat intake and RA. If one study reported red meat intake by range, we assigned the midpoint of the lower and upper bound as mean or median was not provided. If the highest dose group was open-ended, the lower limit plus the width of the previous group was supposed as the corresponding consumption of red meat. When lowest dose group was openended, it was deemed zero as the lower bound of the reference group. If the consumption was shown by servings per day, we transformed it into grams per day using standard units of $120 \mathrm{~g}$ [23]. 


\section{Results}

\section{Study selection}

A total of 3230 studies were searched and 11 eligible studies were finally included [8, 11-14, 24-29]. The details are shown in Figure 1. The basic characteristic of the literatures is presented in Table 1. Among 11 studies, there were 4 cohort studies [1112,27,29] and 7 case-control studies [8,13-14,24-26,28]. In cohort studies, a total of 349776 individuals participated, and 5203 participants developed RA. In case-control studies involving 10618 individuals included 3762 RA cases and 6856 controls. The studies were conducted in United States [11-13], United Kingdom [24], China [25], Japan [26], Sweden [8,27], Iran [14,28] and France [29]. Four studies $[11-13,29]$ recruited only women and the rest of them enrolled participators of both genders.

\section{Categorical meta-analysis}

Compared with non/occasional red meat intake, ever red meat intake was not significantly associated with risk of RA (OR: 0.94; $95 \% \mathrm{Cl}$ : 0.77 to 1.15 ; Figure $2 \mathrm{~A}$ ) with high heterogeneity ( $R=91.5 \%$ ). Subgroup analysis showed that the association remained insignificant when stratified by food culture, publication year, quality score, sample size, study design and gender. However, the heterogeneity in the subgroup of western diet in food culture, publication year beyond 2018, quality score $\geq 7$, sample size $\geq 1000$, case-control in study type and female of gender all went down. The results of meta-regression analysis showed food culture might be a potential source of heterogeneity $(P=0.023$; table 2$)$.

In the analysis of highest vs. lowest red meat intake, we excluded studies that only divided the red meat intake group into two groups $[8,16,24,26]$. Therefore, there were 7 studies included [11-13, 24, 27-29]. The forest plot showed that high red meat intake was associated with an increased risk of RA (OR: 1.26; $95 \% \mathrm{Cl}$ : 1.07 to 1.50; Figure 2B). In subgroup analysis, the positive associations were found among the studies with western diet culture, published before 2018, assessed with higher quality, performed by case-control study design or conducted in females. The associations were significant with larger (OR: 1.19; $95 \% \mathrm{Cl}$ : 1.02 to 1.38 ) or smaller (OR: 2.15; $95 \%$ Cl: 1.29 to 3.59) sample size. However, some subgroups could provide no compelling information because the number of included studies was too few (Arab diet: $N=1$; Quality score $<7$ : $N=1$ ). In addition, the heterogeneity was moderate $\left(I^{2}=56.7 \%\right)$ and the source of heterogeneity has not been found in meta-regression analysis (table 2 ).

Sensitivity analysis showed that no specific study affected the overall estimate. At the same time, there was no publication bias in the two parts of categorical meta-analysis ( $P=0.876$ and 0.230 of Begg's test respectively; $P=0.766$ and 0.119 of Egger's test respectively).

\section{Dose-response relationship between red meat and RA}

Four studies $[11,24,27,29]$ met the requirements for dose-response meta-analysis. A significant non-linear association between red meat intake and RA was found $(P=0.028)$, as depicted in Figure 3. Increased risk of RA was observed when red meat intake ranging from $96 \mathrm{~g} /$ day to $166 \mathrm{~g} /$ day. The most deleterious daily consumption of red meat was $148.5 \mathrm{~g} /$ day (OR: $1.27 ; 95 \% \mathrm{Cl}: 1.07$ to 1.48 ) for risk of RA.

\section{Discussion}

Previous reviews [30-32] summarized the effect of red meat on risk of RA, while have not quantitively synthesized the evidence on the relationship between red meat intake and risk of RA. In the current study, we included a total of 11 observational studies for meta-analysis, and found no overall association between red meat consumption and risk of RA. Interestingly, we found that high red meat intake would promote the occurrence of RA, which suggested a threshold effect with an increased risk of RA only at high levels of red meat consumption. Moreover, a non-linear dose-response relationship was observed.

In the analysis of ever versus non/occasional red meat intake, the large heterogeneity deserved particular attention, which may be partly explained by different diet culture across the 11 studies. It is well known that dietary habits varied dramatically in the countries and regions with different diet culture. Western diet is mainly based on meat, milk, poultry, eggs and other animal food, thus always accompanied by high consumption of saturated fat and trans-fat [33]. Even though dichotomous meta-analysis found null association of red meat intake with risk of diet in countries with western diet culture, highest quintile of red meat intake had an 
elevated risk of RA. On the other hand, studies conducted in countries and regions with oriental diet and Arab diet were relatively limited, more relevant studies should be supplemented for obtaining and confirming stable results.

Seven original studies evaluated the association comparing the highest with the lowest level for red meat intake with a moderate heterogeneity. A majority of included studies had high quality (85.7\%) and large sample size (71.4\%), which provides additional confidence in the findings from our pooled risk estimates. In addition, results from sensitivity analysis were stable and publication bias have not been detected. Furthermore, dose-response relationship meta-analysis suggested that there was statistically significant association between red meat intake and risk of RA when the dose of red meat intake reached a high level (96 166 g/day). Consistently, United Kingdom dietary guidelines endorse limiting the intake of both red and processed meat to $70 \mathrm{~g} / \mathrm{day}$ [34]. The nonsignificant increased risk at red meat intake exceeding $166 \mathrm{~g} /$ day might result from relatively small sample size. Therefore, more epidemiological studies with large sample size are needed to clarify the dose-response relationship.

A positive association between high red meat intake and risk of RA is biological plausible [35-37]. One possible mechanism is that red meat intake affects the development of RA through iron cycle, since red meat is rich in iron, which is easy to accumulate in rheumatoid synovium and causes tissue damage [38-39]. Another explanation is the high collagen content in red meat. Pattison DJ [24] et al. demonstrated that individuals with high intake of red meat were at increased risk of RA because they are more likely to be sensitized to collagen and produce anti-collagen antibodies. Moreover, Stamp LK et al [40] suggested that abundant arachidonic acid (AA) in red meat raises the risk of RA. When AA is ingested in humans, it goes through a cascade reaction to produce eicosanoid with pro-inflammatory properties. The saturated fat in higher levels of red meat also can increase the risk of RA. Saturated fatty acids could translocate lipopolysaccharide toxin and release it into the bloodstream, thus stimulating the immune system and enhance inflammation [41].

There were some limitations should be noted. First, statistically significant heterogeneity among studies was observed. However, the use of random-effects model was allowed to take the heterogeneity among studies into account. Second, the definition of red meat may be not inclusive of all dietary sources of animal meat, nor they have been widely acknowledged across the different studies. Therefore, development and application of universally agreed definitions of red meat subtypes are unavoidable steps in future epidemiological studies aimed to investigate the association of red meat intake with risk of RA. Third, cutoff value of distinguishing between high and low consumption of red meat was diversiform in the included studies, which might introduce bias in an unpredictable direction of categorical meta-analysis. Finally, the imprecise measurement of red meat intake along with recall bias might affect the estimation of the association between red meat intake and risk of RA.

\section{Conclusion}

In conclusion, the meta-analysis showed that high red meat intake is associated with an increased risk of RA. However, high-quality prospective studies that employ standardized assessments of red meat intake and unified definitions of red meat levels are warranted, as well as the mechanistic studies to clarify the aetiologic pathways through which high red meat intake may lead to RA incidence.

\section{Abbreviations}

AA Arachidonic acid

$\mathrm{Cl}$ Confidence interval

HR Hazards ratio

NHS Nurses' Health Study

NOS Newcastle-Ottawa Scale

OR Odds ratio

RA Rheumatoid arthritis 
RR Relative risk

SD Standard deviation

SMD Standardized mean difference

\section{Declarations}

Ethics approval and consent to participate Not applicable.

Disclosure statement The authors have declared no conflicts of interest.

Consent for publication Not applicable.

Availability of data and materials All data generated or analyzed during this study are included in this published article.

Competing interests The authors declare that they have no competing interests.

Funding This work was supported by grants from the National Natural Science Foundation of China (81973663), Natural Science Foundation of Zhejiang Province

(No. LQ20H260008), Medical Health Science and Technology Project of Zhejiang Provincial Health Commission (2020KY195), Zhejiang Chinese Medical University Foundation (2020ZG16).

Authors' contributions Ye D conceived and designed the study. Chen W and Liu K performed literature search. Sang X and Zhuang Y assessed the quality of included studies according NOS. Ye D resolved the argument between Chen W and Liu K. Chen W, Liu K, Su Q and Hu Y performed data analysis. Chen W drafted the manuscript and He Z, Huang $L$ and Mao Y revised the manuscript. All authors read and approved the final manuscript.

Acknowledgements The authors sincerely thank the researchers and participants of the original articles for their collection and management of data resources.

\section{References}

1. Mclnnes IB, Schett G. Pathogenetic insights from the treatment of rheumatoid arthritis. Lancet. 2017;389(10086):2328-37.

2. Safiri S, Kolahi AA, Hoy D, Smith E, Bettampadi D, Mansournia MA, Almasi-Hashiani A, Ashrafi-Asgarabad A, Moradi-Lakeh M, Qorbani M, Collins G, Woolf AD, March L, Cross M. Global, regional and national burden of rheumatoid arthritis 1990-2017: a systematic analysis of the Global Burden of Disease study 2017. Ann Rheum Dis. 2019;78(11):1463-71.

3. Wasserman AM. Diagnosis and management of rheumatoid arthritis. Am Fam Physician. 2011;84(11):1245-52.

4. Sugiyama D, Nishimura K, Tamaki K, et al. Impact of smoking as a risk factor for developing rheumatoid arthritis: a metaanalysis of observational studies. Ann Rheum Dis. 2010;69(1):70-81.

5. Adab P, Jiang CQ, Rankin E, et al. Breastfeeding practice, oral contraceptive use and risk of rheumatoid arthritis among Chinese women: the Guangzhou Biobank Cohort Study. Rheumatology. 2014;53:860-6.

6. Stolt P, Kallberg H, Lundberg I, Sjogren B, Klareskog L, Alfredsson L. Silica exposure is associated with increased risk of developing rheumatoid arthritis: results from the Swedish EIRA study. Ann Rheum Dis. 2005;64:582-6.

7. Olsson AR, Skogh T, Wingren G. Aetiological factors of importance for the development of rheumatoid arthritis. Scand J Rheumatol. 2004;33(5):300-6.

8. Johansson K, Askling J, Alfredsson L, et al. Mediterranean diet and risk of rheumatoid arthritis: a population-based casecontrol study. Arthritis Res Ther. 2018;20:175.

9. Rosell M, Wesley AM, Rydin K, Klareskog L, Alfredsson L. EIRA study group. Dietary fish and fish oil and the risk of rheumatoid arthritis. Epidemiology. 2009;20(6):896-901.

10. Song GG, Bae SC, Lee YH. Association between vitamin D intake and the risk of rheumatoid arthritis: a meta-analysis. Clin Rheumatol. 2012;31(12):1733-9. 
11. Hu Y, Sparks JA, Malspeis S, et al. Long-term dietary quality and risk of developing rheumatoid arthritis in women. Ann Rheum Dis. 2017;76(8):1357-64.

12. Krok-Schoen JL, Brasky TM, Hunt RP, et al. Dietary Long-Chain n-3 Fatty Acid Intake and Arthritis Risk in the Women's Health Initiative. Acad Nutr Diet. 2018;118(11):2057-69.

13. Shapiro JA, Koepsell TD, Voigt LF, et al. Diet and rheumatoid arthritis in women: a possible protective effect of fish consumption. Epidemiology. 1996;7(3):256-63.

14. Rambod M, Nazarinia M, Raieskarimian F. The impact of dietary habits on the pathogenesis of rheumatoid arthritis: a casecontrol study. Clin Rheumatol. 2018;37(10):2643-8.

15. Benito-Garcia E, Feskanich D, Hu FB, Mandl LA, Karlson EW. Protein, iron, and meat consumption and risk for rheumatoid arthritis: a prospective cohort study. Arthritis Res Ther. 2007;9(1):R16.

16. Stang A. Critical evaluation of the Newcastle-Ottawa scale for the assessment of the quality of nonrandomized studies in meta-analyses. Eur J Epidemiol. 2010;25(9):603-5.

17. Higgins JP, Thompson SG, Deeks JJ, et al. Measuring inconsistency in meta-analyses. BMJ. 2003;327(7414):557-60.

18. Chinn S. A simple method for converting an odds ratio to effect size for use in meta-analysis. Stat Med. 2000;19:3127-31.

19. Hozo SP, Djulbegovic B, Hozo I. Estimating the mean and variance from the median, range, and the size of a sample. BMC Med Res Methodol. 2005;20:5:13.

20. Begg CB, Mazumdar M. Operating characteristics of a rank correlation test for publication bias. Biometrics. 1994;50(4):1088101.

21. Egger M, Davey SG, Schneider M, et al. Bias in meta-analysis detected by a simple, graphical test. BMJ. 1997;315(7109):62934.

22. Greenland S, Longnecker MP. Methods for trend estimation from summarized dose-response data, with applications to metaanalysis. Am J Epidemiol. 1992;135:1301-9.

23. Wiseman M. Food, nutrition, physical activity, and the prevention of cancer: a global perspective. Proc Nutr Soc. 2008;67(3):253-6.

24. Pattison DJ, Symmons DPM, Lunt M, et al. Dietary risk factors for the development of inflammatory polyarthritis: Evidence for a role of high level of red meat consumption. Arthritis Rheum. 2004;50(12):3804-12.

25. He J, Wang Y, Feng M, et al. Dietary intake and risk of rheumatoid arthritis-a cross section multicenter study. Clin Rheumatol. 2016;35(12):2901-8.

26. Matsumoto $Y$, Sugioka $Y$, Tada M, et al. Monounsaturated fatty acids might be key factors in the Mediterranean diet that suppress rheumatoid arthritis disease activity: The TOMORROW study. Clin Nutr. 2018;37(2):675-80.

27. Sundstrm B, Ljung L, Giuseppe DD. Consumption of Meat and Dairy Products Is Not Associated with the Risk for Rheumatoid Arthritis among Women: A Population-Based Cohort Study. Nutrients. 2019;11(11):2825.

28. Mosalmanzadeh N, Jandari S, Soleimani D, Shadmand Foumani Moghadam MR, Khorramrouz F, Araste A, Molavi SF, Fakhlaie R, Jokar M, Rezvani R. Major dietary patterns and food groups in relation to rheumatoid arthritis in newly diagnosed patients. Food Sci Nutr. 2020;8(12):6477-86.

29. Nguyen Y, Salliot C, Gelot A, et al. Mediterranean diet and risk of rheumatoid arthritis: findings from the French E3N-EPIC cohort study. Semin Arthritis Rheum. 2020;73(1):69-77.

30. Zaccardelli A, Friedlander HM, Ford JA, Sparks JA. Potential of Lifestyle Changes for Reducing the Risk of Developing Rheumatoid Arthritis: Is an Ounce of Prevention Worth a Pound of Cure? Clin Ther. 2019;41(7):1323-45.

31. Pattison DJ, Symmons DP, Young A. Does diet have a role in the aetiology of rheumatoid arthritis? Proc Nutr Soc. 2004;63(1):137-43.

32. Grant WB. The role of meat in the expression of rheumatoid arthritis. Br J Nutr. 2000;84(5):589-95.

33. Philippou E, Nikiphorou E. Are we really what we eat? Nutrition and its role in the onset of rheumatoid arthritis. Autoimmun Rev. 2018;17(11):1074-7.

34. The Eatwell Guide. In: The Eatwell Guide. Public Health England. 2016. https://www.gov.uk/government/publications/theeatwell-guide. Accessed 22 Aug 2021. 
35. Dourado E, Ferro M, Sousa Guerreiro C, Fonseca JE. Diet as a Modulator of Intestinal Microbiota in Rheumatoid Arthritis. Nutrients. 2020;14(11):3504. 12(.

36. Gioia C, Lucchino B, Tarsitano MG, lannuccelli C, Di Franco M. Dietary Habits and Nutrition in Rheumatoid Arthritis: Can Diet Influence Disease Development and Clinical Manifestations? Nutrients. 2020;12(5):1456.

37. Alwarith J, Kahleova H, Rembert E, Yonas W, Dort S, Calcagno M, Burgess N, Crosby L, Barnard ND. Nutrition Interventions in Rheumatoid Arthritis: The Potential Use of Plant-Based Diets. Front Nutr. 2019;6:141.

38. Morris CJ, Blake DR, Wainwright AC, Steven MM. Relationship between iron deposits and tissue damage in the synovium: an ultrastructural study. Ann Rheum Dis. 1986;45(1):21-6.

39. Blake DR, Hall ND, Bacon PA, et al. The importance of iron in rheumatoid disease. Lancet. 1981;2(8256):1142-4.

40. Stamp LK, James MJ, Cleland LG. Diet and rheumatoid arthritis: a review of the literature. Semin Arthritis Rheum. 2005;35(2):77-94.

41. Fritsche KL. The science of fatty acids and inflammation. Adv Nutr. 2015;6(3):293S-301S.

\section{Tables}

Table 1 Characteristics of included studies 


\begin{tabular}{|c|c|c|c|c|c|c|c|c|}
\hline Author, year & Country & $\begin{array}{l}\text { Study } \\
\text { type }\end{array}$ & Age/Sex & $\begin{array}{l}\text { Research } \\
\text { period }\end{array}$ & $\begin{array}{l}\text { Cases/coho } \\
\text { controls }\end{array}$ & size or Quantity & $\begin{array}{l}\text { Type of } \\
\text { metric }\end{array}$ & Quality \\
\hline $\begin{array}{l}\text { Shapiro JA, } 1996 \\
{[13]}\end{array}$ & USA & $\begin{array}{l}\text { case- } \\
\text { control }\end{array}$ & $\begin{array}{l}18- \\
64 / \text { Female }\end{array}$ & $1971-1975$ & $324 / 1245$ & $\begin{array}{l}4.4 \sim 6.5 \text { servings/week vs. }<4.4 \\
\text { servings/week } \\
6.5 \sim 9.1 \text { servings/week vs. }<4.4 \\
\text { servings/week } \\
>9.1 \text { servings/week vs. }<4.4 \\
\text { servings/week }\end{array}$ & OR & 7 \\
\hline $\begin{array}{l}\text { Pattison DJ, } 2004 \\
{[24]}\end{array}$ & UK & $\begin{array}{l}\text { case- } \\
\text { control }\end{array}$ & 45-75/Both & 1993-1997 & $88 / 176$ & $\begin{array}{l}25.5-58.0 \mathrm{~g} / \text { day vs. }<25.5 \mathrm{~g} / \text { day } \\
>58.0 \mathrm{~g} / \text { day vs. }<25.5 \mathrm{~g} / \text { day }\end{array}$ & OR & 6 \\
\hline He J, $2016^{[25]}$ & China & $\begin{array}{l}\text { case- } \\
\text { control }\end{array}$ & NA/Both & $2012-2013$ & $968 / 1037$ & Mean (SD) & $\begin{array}{l}\text { SMD to } \\
\text { OR }\end{array}$ & 4 \\
\hline $\mathrm{Hu} \mathrm{Y,} 2017^{[11]}$ & USA & cohort & $\begin{array}{l}25- \\
55 / \text { Female }\end{array}$ & $1984-2011$ & $\begin{array}{l}1007 / 170 \\
996\end{array}$ & $\begin{array}{l}\text { Median: } 0.72 \text { servings/day vs. } 0.37 \\
\text { servings/day } \\
\text { Median: } 1.04 \text { servings/day vs. } 0.37 \\
\text { servings/day } \\
\text { Median: } 1.50 \text { servings/day vs. } 0.37 \\
\text { servings/day }\end{array}$ & HR & 7 \\
\hline $\begin{array}{l}\text { Matsumoto Y, } 2017 \\
{[26]}\end{array}$ & Japan & $\begin{array}{l}\text { case- } \\
\text { control }\end{array}$ & NA/Both & $2010-2011$ & $208 / 205$ & Mean (25th-75th percentiles) & $\begin{array}{l}\text { SMD to } \\
\text { OR }\end{array}$ & 5 \\
\hline $\begin{array}{l}\text { Johansson K,2018 } \\
\text { [8] }\end{array}$ & Sweden & $\begin{array}{l}\text { case- } \\
\text { control }\end{array}$ & $\begin{array}{l}\text { Median: } \\
\text { 53/Both }\end{array}$ & $2005-2014$ & $\begin{array}{l}1721 / 3 \\
667\end{array}$ & Mean (SD) & $\begin{array}{l}\text { SMD to } \\
\text { OR }\end{array}$ & 7 \\
\hline $\begin{array}{l}\text { Krok-Schoen JL, } \\
2018^{[12]}\end{array}$ & USA & cohort & $\begin{array}{l}55- \\
79 / \text { Female }\end{array}$ & 1993-1998 & $\begin{array}{l}3348 / 80 \\
551\end{array}$ & $\begin{array}{l}0.303 \sim 0.562 \text { servings/day vs. } \\
<0.303 \text { servings/day } \\
0.562 \sim 0.932 \text { servings/day vs. } \\
<0.303 \text { servings/day } \\
0.932 \text { servings/day vs. }<0.303 \\
\text { servings/day }\end{array}$ & HR & 7 \\
\hline $\begin{array}{l}\text { Rambod M, } 2018 \\
{[14]}\end{array}$ & Iran & $\begin{array}{l}\text { case- } \\
\text { control }\end{array}$ & $>18 /$ Both & $2015-2016$ & $403 / 426$ & Mean (SD) & $\begin{array}{l}\text { SMD to } \\
\text { OR }\end{array}$ & 6 \\
\hline $\begin{array}{l}\text { Sundström B, } 2019 \\
{[27]}\end{array}$ & Sweden & cohort & 54-89/Both & $2003-2014$ & $\begin{array}{l}368 / 35 \\
600\end{array}$ & $\begin{array}{l}4 \sim 7 \text { servings/week vs. } \leq 4 \\
\text { servings/week } \\
7 \sim 10 \text { servings/week vs. } \leq 4 \\
\text { servings/week } \\
>10 \text { servings/week vs. } \leq 4 \\
\text { servings/week }\end{array}$ & HR & 8 \\
\hline $\begin{array}{l}\text { Mosalmanzadeh N, } \\
2020 \text { [28] }\end{array}$ & Iran & $\begin{array}{l}\text { case- } \\
\text { control }\end{array}$ & 19-68/Both & $2017-2018$ & $50 / 100$ & $\begin{array}{l}\text { T2 vs. T1 } \\
\text { T3 vs. T1 }\end{array}$ & OR & 8 \\
\hline Nguyen Y, 2020 [29] & France & cohort & $\begin{array}{l}40- \\
65 / \text { Female }\end{array}$ & $1990-2017$ & $\begin{array}{l}480 / 62 \\
629\end{array}$ & $\begin{array}{l}51 \sim 104 \mathrm{~g} / \text { day vs. }<51 \mathrm{~g} / \text { day } \\
>104 \mathrm{~g} / \text { day vs. }<51 \mathrm{~g} / \text { day }\end{array}$ & HR & 8 \\
\hline
\end{tabular}

Abbreviation: HR: hazard ratio; NA: not available; OR: odds ratio; SD: standard deviation; SMD: standardized mean difference; T: tertiles.

Table 2 Subgroup analysis and meta-regression between red meat intake and risk of RA. 


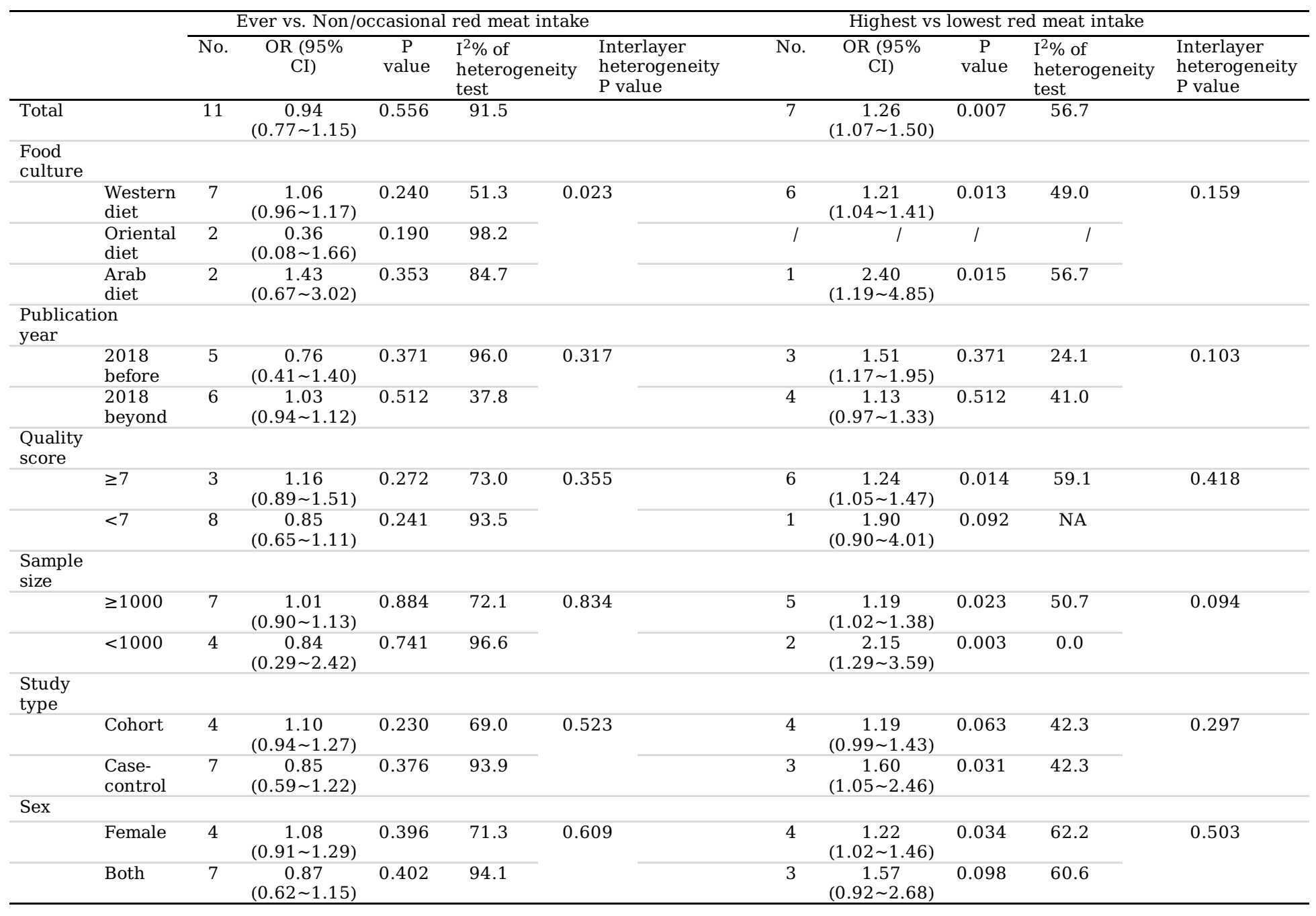

Figures 


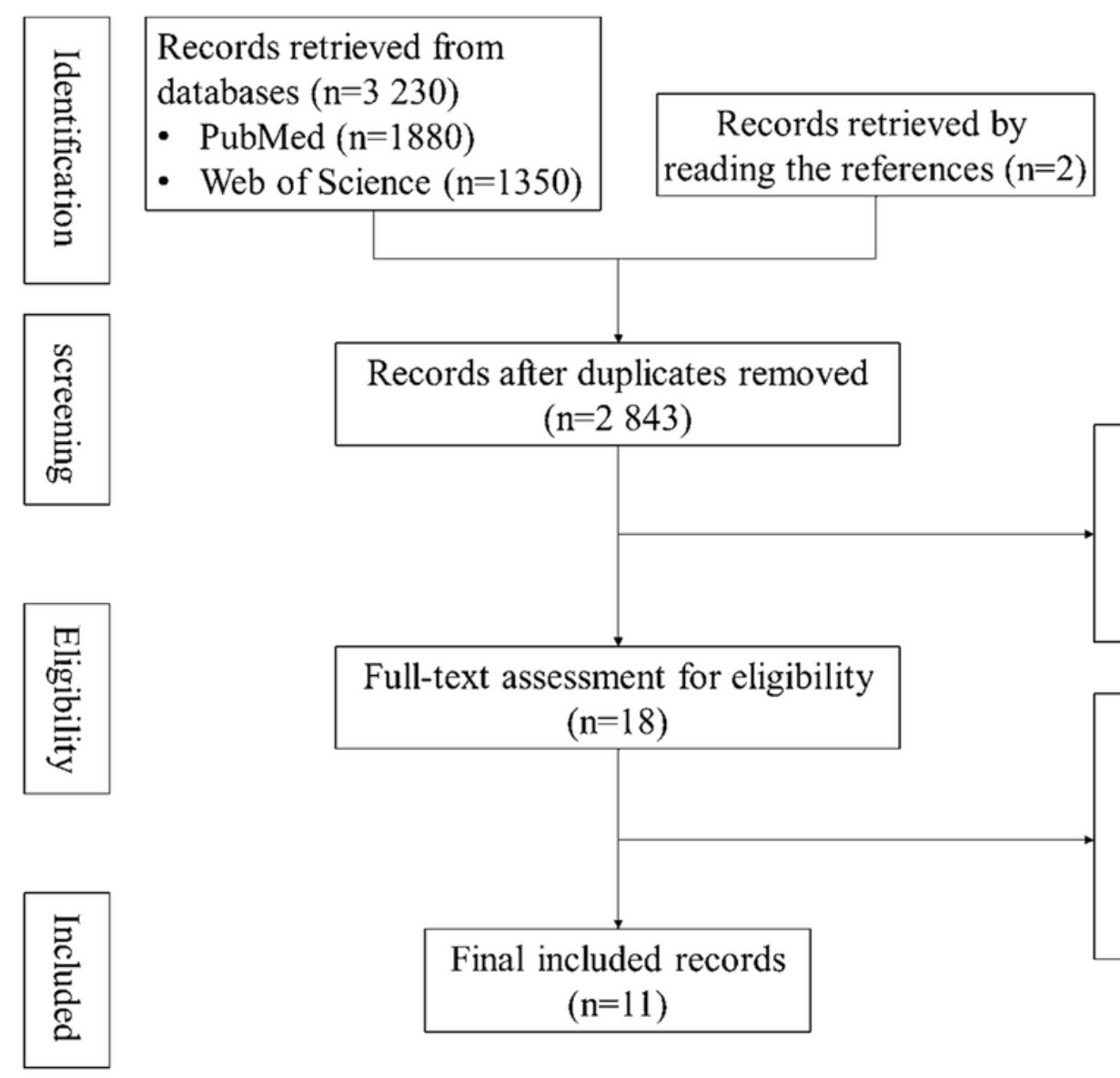

Exclusion of records $(\mathrm{n}=2825)$

- Not relevant to the topic $(n=2760)$

- No full-text studies $(n=4)$

- Review and Meta-analysis (61)

Exclusion of records $(\mathrm{n}=7)$

- Data missing $(n=4)$

- Same study population $(\mathrm{n}=2)$

- Inconsistent definition of exposure factors $(\mathrm{n}=1)$

Figure 1

The flow diagram of study selection.

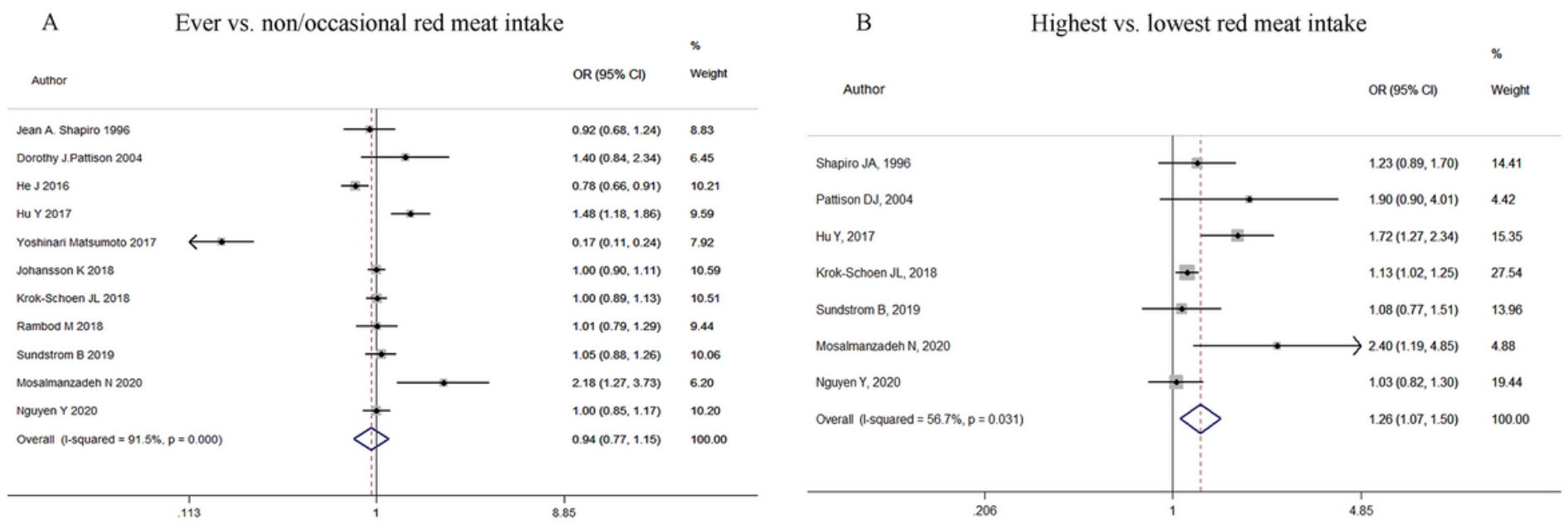

Figure 2

Association between red meat intake and risk of RA comparing ever vs. non/occasional (A) and highest vs. lowest (B). 


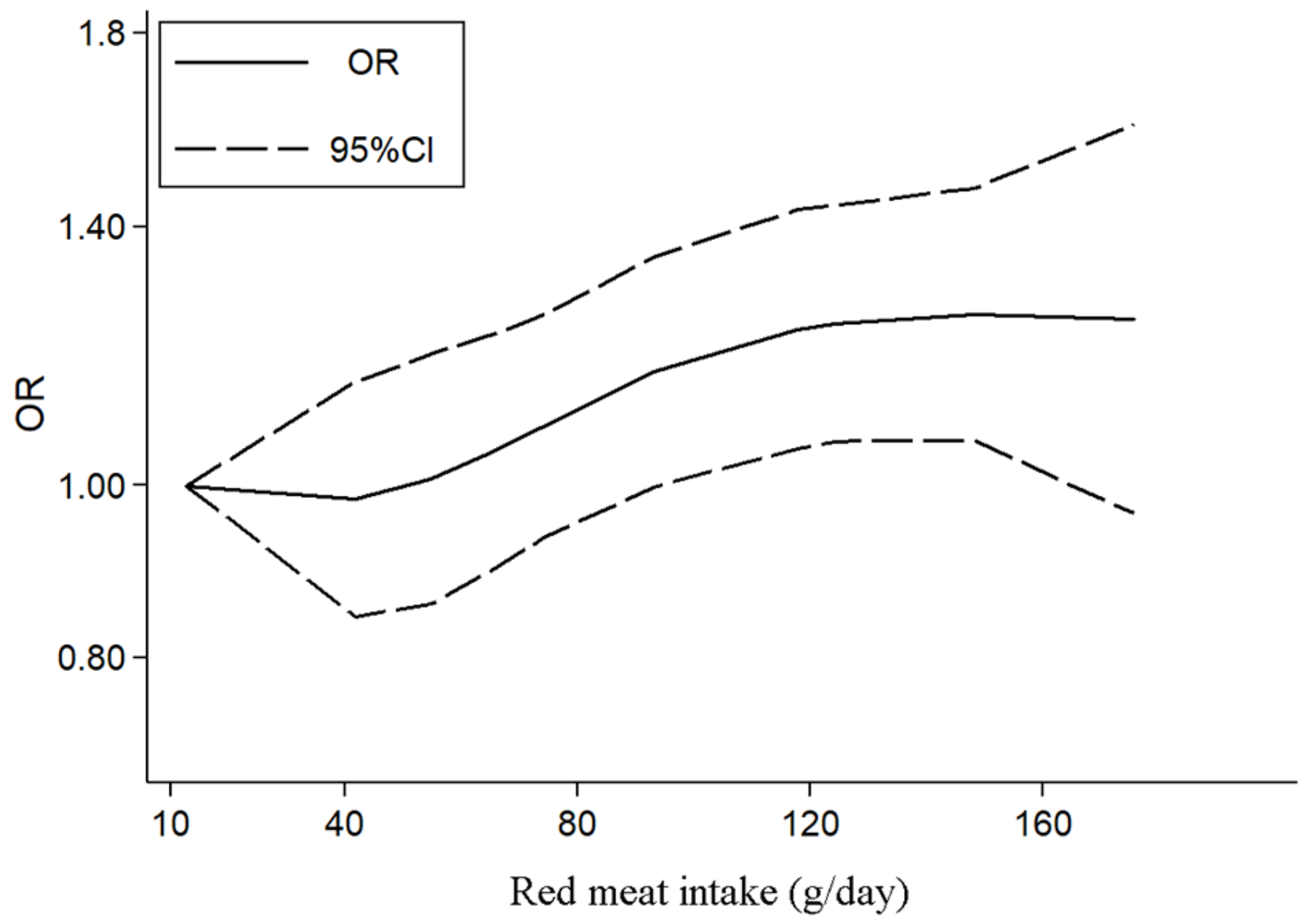

Figure 3

Dose-response relationship between red meat and risk of RA.

\section{Supplementary Files}

This is a list of supplementary files associated with this preprint. Click to download.

- SupplementaryTable1.docx 